\title{
Impact of Foreign Direct Investment on Employment Generation in Nigeria: A Statistical Investigation
}

\author{
${ }^{1}$ Okoro H. Matthew, ${ }^{2}$ Atan A. Johnson \\ ${ }^{1,2}$ Department of Economics, University of Uyo, Nigeria
}

\begin{abstract}
While we believe that sample issues and measurement errors could contribute to the complexity of FDI-economic growth empirical analyses, the present work suggests that $99 \%$ of the mixed results are attributable to poor statistics, data treatment and model specifications.
\end{abstract}

\section{Introduction}

It is thought that Foreign Direct Investment (FDI), as a key element of globalization and the world economy, is a driver of employment, technological progress, productivity improvement, and ultimately, economic growth (Asiedu, 2002). Some authors (see for example, Smith, 1997; Quazi 2007) submit that FDI fulfils the development, foreign exchange, investment, and tax revenue gaps in developing nations. The contribution of FDI to the growth economy of the world has, however, been strongly disputed for over six decades (see Katerina et al., 2004, for a historical review of early works). Expectedly, an interested reader will, no doubt, be prompted to inquire whether the truth on the growth impact of FDI has been established. Similar questions might be "why is the subject an object of debate? How is the controversy settled? Or what efforts have been made towards resolving the issue"?

While the first question has a universally acceptable and a simple answer - NO, the solutions to the rest of the questions are like the proverbial sixty-four-thousand-dollar questions. "Why is FDI a subject of much debate" is a question that, to the best of our knowledge, has not received reasonable attention of FDI-growth related investigations. Rather, what almost every author does is to enthusiastically enumerate the list of opposing publications on FDI-growth studies. After such adumbrations, the same authors will, amusingly, fall victim of finding negative or positive impact of FDI on the economy without proving while he/she is falling on either camp or while those on the other fence might altogether, be wrong. This is awful as it smacks of laxity and lack of commitment towards resolving the problem.

The question of how the problem is settled has its answer in the first question. The debate is ongoing. A number of efforts (see section 2 for a review of some spirited attempts), thought fruitless, have been made towards sorting out the issues. Since FDI-growth impact has remained inconclusive for so long, the topic or debate, will, sooner or later, become unattractive, especially to the public. Instead of increasing the innumerable number of publications that investigate whether FDI has a negative or a positive impact on the economy, we feel that it is time to focus primarily on the reasons why the topic is a subject of confusion. This is the main objective of the present article.

\section{Literature Review}

FDI is an investment made to acquire a lasting management interest (normally $10 \%$ of voting stock) in a business enterprise operating in a country other than that of the investors defined according to residency (World Bank, 1996). There are, nonetheless, other definitions of FDI. This is because it is a complex field as it touches almost all facets of human endeavour. Consequently, its definition as well as its usefulness depends on the investing multinational corporations (MNCs) or the recipient/host country positions. The present review will focus more on the relevance of FDI to the Nigeria economy.

Two schools of thought exist with a strong wall of partition dividing them. On one side are the proforeign international schools that see FDI as adding new resources in terms of capital, technology, managerial skill and technical know-how, productivity gains, and so on, to the host economy. They regard FDI as potent enough to improve the prevailing efficiency in the productive sector, stimulate change for faster economic growth, create jobs, foster growth, and improve the distribution of income by bidding up wages in the host economics.

On the other side of the wall is the opposing dependency school drawing their arrangement from Marist dependency theory. They doubt whether FDI - which do soak up local financial resources for their own profits can bring about industrialization because foreign investors see host economics as merely serving the interest of their home countries in supplying basic needs for their companies. This school views foreign investors as "imperialistic predators" that specialize in exploiting the entire globe for the sake of corporate few as well as creating a wet of political and economic dependence among nations to the detriment of the weaker ones. This 
group thought that foreign investors set artificial prices to extract excessive profits, make insufficient transfer of technology at too high cost, crowds-out domestic investment and exert serious strains on the balance of payment of the host country.

Robu (2010) asserts that FDI is usually sought by countries that are going through the transition period and/or those that face severe structural unemployment. This is the situation of Nigeria. Aremu (1997) noted that Nigeria as one of the developing countries of the world, has adopted a number of measures aimed at accelerating growth and development in the domestic economy. One of such measures is FDI attraction. The realization of the importance of FDI had informed the radical and pragmatic economic reforms introduced since the mid1980 s by the Nigerian government. According to Ojo (1998), the reforms were designed to increase the attractiveness of Nigeria's investment opportunities and foster the growing confidence in the economy so as to encourage foreign investors in Nigeria. The reforms resulted in the adoption of liberal and market-oriented economic policies, the stimulation of increased private sector participation and the elimination of bureaucratic obstacles which hinders private sector investments and long-term profitable business operations in Nigeria. One of the targets of these reforms is to encourage the existence of foreign multinational corporations (MNCs) and other private investors in some strategic sectors of the Nigeria economy like the oil industry, banking industry, communication industry and others. Since the enthronement of democracy in 1999, the government of Nigeria has taken a number of measures necessary to woo foreign investors in the country. Some of these measures include the repeal of laws that are inimical to the foreign investment growth, promulgation of investment laws, various overseas trips for image laundry by some presidents among others. Umah (2007) asserts that the Nigeria government has instituted various institutions, policies and laws aimed at encouraging foreign investors.

These efforts have not been in vain as the country has witnessed amazing inflow of FDI in the recent times (Adofu, 2010). But whether FDI plays the acclaimed role of pushing the economy forward is a topic that is currently generating a dramatic wave among researchers and economic law makers. The policymakers do not have much analytical tool to assess the performance of FDI in Nigeria economy. They generally add their voice by citing other countries of the world that actively engage in FDI and thus, hopefully, argue that FDI might be playing the same role in Nigeria's economy. They rather look forward to the empirical analysts to show them the way forward.

But the empirical literatures do not have one voice as well. Some of the authors that find positive linkages between FDI and economic development in Nigeria are Aluko (1961), Brown (1962), Oyaide (1977), Obinna (1983), Ariyo (1998), Chete (1998), Anyanwu (1998), Oseghale and Amenkhienan (1987), Okodu (2009). Others such as Oyinlola (1995), Badeji and Abayomi (2011) and Otepola (2002) argue that FDI retard economic growth in Nigeria. Amidst those who report positive connections are those that find that the contribution is statistically insignificant (e.g. Aynwele, 1997; Adofu, 2010) and as such frown at, according to Adofu (2010), "undue attention" given to FDI in Nigeria. The implication of the conflicting economic advice that arises from these multifarious results is palpable.

The question that hangs on all lips at this stage, as indicated in section one is: "what is responsible for these contradictions and what could be the way out of the dilemma". A number of explanations have been given in an attempt to explain the prevalent lack of consensus on the catalytic role of FDI on the economic growth. Attempt will be made in the next section to examine some of the major reasons fingered by researchers as the kingpin that upset the apple cart.

\subsection{WHY IS FDI-GROWTH IMPACT AMBIGUOUS?}

Understandably, empirical literatures that find positive impact would feel at ease since positive impact is in tandem with the aprori expectations. Contrarily, publications that find negative results feel somewhat challenged and, consequently, do respond with all sorts of colourful reasons to argue away the positive role of FDI on the economy. Some of the competing theories are presented. Early works on FDI claim that the target countries of FDI receive very little benefits - because most benefits are transferred to the multinational company's country (Singer, 1950; Prebisch, 1968). Although FDI raises the level of investment and, perhaps, the productivity as well as consumption in the country, FDI lowers the rate of growth due to price distortions or misallocations of resources (Singer, 1950; Presbisch, 1968). Bos, Sanders and Secchi (1974) found a negative relationship between FDI and economic growth of the recipient countries. The reason was blamed on profit repatriations. Additionally, price distortions due to protectionism and monopolization as well as natural resources depletion are reasons adduced to explain the negative impact. Saltz (1992) equally find a negative correlation between FDI and growth and explained that the level of output of a host country is bound to stagnate if FDI enjoys monopolization and pricing transfers. This is because such incentives will cause under utilization of labour which will in turn cause a lag in the level of domestic consumption demand and eventually will lead growth to stagnate. Other reasons are lack of the envisaged forward and backward linkages between FDI and growth (Aitken et. al. 1997), transnational and corporations and firms (TNCs) tend to locate in high productive industries and could, therefore, force less productive firms to exit (Smarzynska, 2002), crowding out of 
domestic firms and possible contraction in the total industry size, unemployment (Cotton and Ramachandran, 2001), the host country's capability to absorb the foreign technology and the type of investment climate or FDI the prevailing FDI policies (Obwona, 2004). Obviously, the foregoing reasons are mainly speculative.

Pragmatic reasons, stemming more directly from data analyses are measurement errors, sample issues, the use of cross country data and finally, errors arising from different methods of analysis. While measurement errors are expected to be a universal problem in econometrics, the rest of the problems can either be completely eliminated or greatly minimized as they are more or less dependent on the researcher's expertise as well as dedication with respect to superficial or rigorous analyses. Specifically, methodological differences should not be an issue in FDI-growth related analysis. This is because statisticians, like their twine mathematicians, will surely arrive at the same solution, the method adopted, notwithstanding. Whether a quadratic equation is tackled using the graph method, the method of factorization, by the use of the almighty formula or by the method of completing the square, the solution is invariant. This is the basic idea of using different statistical or mathematical approaches to investigate the FDI-growth relationship.

Violating this principle is surely not good as it would imply creating an un-existing or a peculiar field of mathematics or statistics. Although most development literatures indicate that the type of methodology employed could be a crucial determinant of FDI-growth impact results, we do not think that that should be the case. Rather, given the same data, mathematical principles and ethics calls for the same answer. The idea of dilemma and uncertainties are the domains of theoreticians, irreconcilable with experimental or empirical studies.

Obviously, reasonable attention has been given to endogeneity problems (Ayanwele, 2007; Okon et al. 2012; Badeji and Abayomi, 2011); the confusion that might arise from country wide data has been removed by using country or Nigeria specific data (Aluko,1961; Brown,1962; Oyaide, 1977; Obinna,1983; Ariyo, 1998; Chete, 1998; Anyanwu, 1998; Oseghale and Amenkhienan, 1987; Eke et al. 2003; Okodu, 2009; Oyinlola, 1995; Badeji and Abayomi, 2011; Otepola, 2002; Akinlo, 2004; Anynwale, 2007; Adofu, 2010; Endozien, 1968 ) and yet the position of FDI on Nigeria remains questionable.

Any interested reader will, no doubt, think of a turning point with regard to the current methodology, which, apparently, has failed to unravel the mystery. An approach that significantly departs from the current practice is, indeed, required in order to meaningfully test the hypothesis that FDI is an economic growth promoter. Heuristic intuition might be invoked at this stage if FDI-growth study is to be looked at from a different point of view. Such approach is the object of this presentation. But before furthering this, it is important to note here that the general tool used by over $99 \%$ of econometricians in the study of FDI-growth impact is the ordinary least squares (OLS) regression technique. The method is such an indispensable tool in econometrics that Gujurati (2004) referred to it as the bread-and-butter tool of econometrics. Although the method is, unarguably, the plumb line of an economist, it is fraught with many problems that are so difficult to handle.

Heteroscedasticity, multicollinearity, the presence of unit root, co-integration and autocorrelation are some of the problems associated with the use of OLS analytical tool. Multicollinearity, unit root and autocorrelation appear to be the chief among these problems. Specifically, the presence of autocorrelation can significantly bias the result of OLS and, ultimately, induce spurious regression. It is such an intractable problem that many authors merely speculate its presence in a data without accounting or correcting for it. The widely used Durbin-Watson (DW) statistics only serves as a means of detecting the presence of autocorrelation but offers no solution where it exists.

The next section will attempt to illustrate how this confusion about the place of FDI on the economy of Nigeria can be minimized. Instead of introducing a new work, we will use a previously analyzed FDI data (Salami and Oyewale, 2013), as a case study, to explain that superficial analyses could be the brain behind the ambiguity in the submissions of empirical literatures on FDI-economic growth connection.

\subsection{DATA SOURCE}

\section{Data Source And Methodology}

The data is taken from the work of Salami and Oyewale (2013) published in International Journal of Economic Development Research and Investment. The authors use the data to examine the impact of FDI on economic growth in Nigeria.

\subsection{ECONOMETRIC RESEARCH METHODOLOGY 3.2.1 INTRODUCTION}

Due to the indeterministic nature as well as the complex interplay between the economic growth variables, research methodology is of great importance to the economist. This is because the results and conclusions drawn from the research depend greatly on the method adopted. There is, thus, a need for a researcher to understand and hence, explain in details, the various techniques employed in a particular study. 
This will give some other person the room to assess the validity of the researcher's claim. This is the main focus of this section.

\subsubsection{CONCEPTUAL FRAMEWORK AND DESCRIPTION OF VARIABLES}

This section intends to highlight the nature and measurement of these economic growth variables around which the whole study revolves while the next section concentrates on the methodology of analysis of these variables. The chief corner-stone among these variables are FDI and employment rate and they are, therefore, considered first.

(i) FDI: Tadaro (1999) defines FDI as investment by large multinational corporations with headquarters in the developed nation of the world. To buttress the definition, Makola (2003) noted that FDI is the primary means of transfer of private capital (i.e. physical or financial), technology, personnel and access to brand names and marketing advantage. Viewed as a private investment, some authors (e.g. Adofu, 2010) refer to it as private foreign direct investment (FPI). Amadi (2002) explains that FDI is not just an international transfer of capital but rather, the extension of enterprise from its home country which involves flows of capital, technology and entrepreneurial skills to the host country where they are combined with local factors in the production of goods for local and for export markets (Root,1984).

Still on the definition of FDI as a strong world development indicator, one of the pioneering study on FDI, Hymer (1960), described FDI as asset transfer by the formation of subsidiaries or affiliates abroad, without lots of control. The summary of these definitions is that FDI means asset (capital, technology, managerial abilities) transfer from the developed to the developing world. This is the reason why FDI is regarded as an important world development yardstick.

(ii) EMPLOYMENT RATE (EMR): This refers to the total annual employment growth rate in Nigeria. It is measured with reference to the total population of the Nigeria citizenry that are ready and willing to work.

(iii) EXPORT: This refers to the amount of goods export to other countries per annum. It is a good indicator of economic progress and is expected to be positively connected with EMR growth and hence, employment rate.

(iv) IMPORT (IMP): This variable is used to describe the amount of goods imported per annum from other countries of the world into Nigeria. Whether it impacts positively or not on the rate of employment in Nigeria depends, to a great extent, on the type of goods being imported - finished or raw material goods.

(v) EXCHENGE RATE (EXR): This is the price of one currency in terms of another. It is usually defined in two ways: Domestic currency units per unit of foreign currency or foreign currency per unit of the domestic currency. High exchange rate may discourage investors. Devaluation of local currency, for example, will lead to increase in trade volumes and competiveness. Its connection with EMR tells whether Nigeria exchange rate policy encourages economic growth or not.

(vi) INFLATION RATE: This refers to the percentage change in the value of the Wholesale Price Index on a year-on year basis. It effectively measures the change in the prices of a basket of goods and services in a year in Nigeria.

\subsection{MODEL SPECIFICATIONS}

In order to estimate the relationship between FDI and employment rate in Nigeria, the present study will employ single equation models. Ordinary least-square (OLS) method will be used in the present investigation. OLS is, simply, a method of fitting the best straight line to the sample of XY observations.

The central goal of the present work is to investigate the role of FDI on the employment rate in Nigeria. Other economic variables believed to impact on employment are also included for completion and comparison purposes. A function that relates these parameters can be of the form:

$$
\text { EMR }=\mathrm{f}(\text { FDI, EXP, IMP, EXR, INF) }
$$

\subsubsection{TRADITIONAL REGRESSION MODEL}

Suppose that equation 1 has a linear relationship, it can be transformed as:

$$
E M R_{t}=\beta_{0}+\beta_{1} F D I_{t}+\beta_{2} E X P_{t}+\beta_{3} I M P+\beta_{4} E X R+\beta_{5} I N F+u
$$

$$
2
$$

\subsubsection{STADNARDIZED REGRESSION MODEL}

Regression on standardized variable has a number of advantages over the traditional regression model (equation 2). In order to exploit these advantages, standardized model (equation 3 ) is also run.

$$
E M R_{t}=\beta_{1} F D I_{t}+\beta_{2} E X P_{t}+\beta_{3} I M P+\beta_{4} E X R+\beta_{5} I N F+u
$$

3

3.3.3 LAGGED OLS VARIABLE MODEL

Gujarati (2004) asserts that time lag exists between some economic growth variables. Wilhelms and Witter 
(1998) equally emphasize the need for using the lagged values of the explanatory variables of economic growth data. It is believed that it takes one to six years for FDI projects to exert any significant effects on the economy of a country. This time lag accounts for registration to actual operation. In order to account for this time lag, a model of the form is equally specified:

$$
E M R_{t}=\beta_{1} F D I_{t-1}+\beta_{2} E X P_{t-1}+\beta_{3} I M P_{t-1}+\beta_{4} E X R_{t-1}+\beta_{5} I N F_{t-1}+u
$$

4

where $\mathrm{i}=1,2,3, \ldots \ldots$

\subsubsection{APRORI EXPECTATION}

The regression models above set out to test if there is a relationship between EMR and FDI. Other variables, believed to impact on the economy, are equally included. The coefficient of FDI is expected to be positive since FDI is believed to boost the rate of employment. The coefficient of export equally expected to be positively related with the employment rate. The coefficient of exchange rate is not certain as it depends on its variability within the time period. The coefficient of inflation is supposed to impact negatively on the employment rate.

\subsubsection{GRANGER CAUSALITY}

Although OLS results can establish the existence of a relationship between two data time series, it cannot explain the direction of the relationship. Since the future cannot predict the past, Granger causality test attempts to establish if changes in FDI precede changes in EMR, that is, FDI causes EMR and not EMR causing FDI. Given:

$$
\begin{gathered}
E M R_{t}=\beta_{0}+\sum \beta_{j} E M R_{t-j}+\sum c_{j} F D I_{t-j}+u_{t} \\
F D I_{t}=\beta_{0}+\sum \beta_{j} F D I_{t-j}+\sum c_{j} E M R_{t-j}+u_{t}
\end{gathered}
$$

Equation (5) postulates that current EMR is related to past values of itself as well as that of FDI, and (6) postulates a similar behaviour for FDI. There are four implications for each of the equations. (i) $E M R \rightarrow F D I$ [EMR causes FDI, unilateral causality]; (ii) FDI $\rightarrow E M R$ [FDI causes EMR, unilateral causality]; (iii) $E M R \leftrightarrow F D I$ [feedback or bilateral causality]; and $E M R-F D I$ [independence].

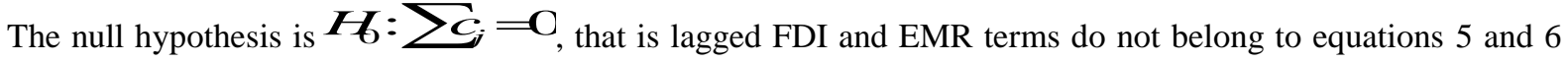
respectively. The symbol $E M R \leftrightarrow F D I$ implies bilateral causality and is explained thus: Bidirectional causality exists between EMR and FDI in the two equations above if the null hypotheses $\boldsymbol{H}: \boldsymbol{\Sigma C}_{j}=\mathrm{O}_{\text {for }}$ the two equations are rejected. The test of significance of the overall fit can be carried out with an F test while the number of lags can be chosen with AIC criteria. The details of granger tests are explained in section 3.5

\subsection{DETAILS OF ANALYSES}

Section 3.3 specifies a number of models ranging from the usual OLS models to granger causality or lagged models. While the ordinary OLS (un-lagged models) is an old and familiar method common in the literatures, other methods such as granger causality test (GCT), unit root test and co-integration test are yet at the infancy stage in the development literatures. Some investigators are in the habit of indicating, for instance, that they conducted GCT but one may have no idea what or how the test is conducted. This section intends to give some little details of these relatively new techniques before quoting the final results in section 4 .

\subsubsection{UNIT ROOT TESTS}

The results of FDI-economic growth can only be useful to the society if policy makers can accept the validity or significance of the results. In order to do any meaningful policy analyses with the OLS results, it is important to distinguish between correlations that arise from a sheer trend (spurious) and one associated with an underlying casual relationship. To achieve this, all the data used in the study are first tested for unit root (non-stationarity) by using the Dickey-Fuller (DF) and the Augmented Dickey-Fuller (ADF) tests. Since our data cannot be mere noise, we assumed them to be stationary data with a constant only or stationary data with a constant and time trend.

The results of unit root tests are presented in Tables 3.1 and 3.2. The data are in linear form in Table 3.1 while they are in log form in Table 3.2. The two results are interestingly different and underscore the need for result validation in FDI-economic growth studies. It is evident that all the variables are stationary at I(1) in table 3.2 whereas table 3.1 presents a different story. While the rest of the variables are stationarity constant at first difference (Table 3.1A), FDI proves to belong to a difference class of signal. Table 3.1B, on the other, suggests that all of the variables are stationarity constant and time trend data.

The implication of the results presented in Tables $3.1 \mathrm{~A}$ and $3.1 \mathrm{~B}$ is that there is a tendency of producing a 
spurious regression result should the data be used in the linear form. This is more likely if the data are time series signals with constant only (Table 3.1A). Investigation of these data using linear form could yield a more valid result if time factor is introduced (Table 3.2). This is a pointer to the superiority of unit root test over other analyses such as correlation, regression and causality test.

TABLE 3.1A: UNIT ROOT TEST FOR STATIONARITY WITH CONSTANT ONLY

\begin{tabular}{|c|c|c|c|c|c|c|}
\hline \multicolumn{7}{|c|}{ UNIT ROOT TEST FOR STATIONARITY WITH CONSTANT ONLY } \\
\hline & & & & & & \\
\hline & VARIABLE & DF & ADF & DF & ADF & Conc \\
\hline 1 & FDI & 0.39 & 0.56 & -2.78 & -2.21 & N.A \\
\hline 2 & EMR & -1.28 & -1.27 & $-3.50 *$ & - & $\mathrm{I}(1)$ \\
\hline 3 & EXP & -2.26 & -1.77 & $-4.80^{* *}$ & - & $\mathrm{I}(1)$ \\
\hline 4 & IMP & -2.28 & -1.87 & $-5.02 * *$ & - & $\mathrm{I}(1)$ \\
\hline 5 & EXR & -0.97 & -0.22 & $-5.65 * *$ & - & $\mathrm{I}(1)$ \\
\hline 6 & INF & -2.06 & -1.45 & $-4.30 * *$ & - & $\mathrm{I}(1)$ \\
\hline
\end{tabular}

Note: From CRITICAL DICKEY-FULLE table, $1 \%$ and $5 \%$ significance level for sample size less than 50 is given as -3.75 and -3.00 respectively. In this table, '**' and '*', represent $1 \%$ and $5 \%$ level of significance respectively.

TABLE 3.1B: UNIT ROOT TEST FOR STATIONARITY WITH CONSTANT AND TIME TREND UNIT ROOT TEST FOR STATIONARITY WITH CONSTANT AND TIME TREND

\begin{tabular}{|c|c|c|c|c|c|c|}
\hline & & \multicolumn{2}{|c|}{ LEVEL } & \multicolumn{2}{|c|}{ 1st Difference } & \multirow[b]{2}{*}{ Conc } \\
\hline & VARIABLES & DF & ADF & DF & ADF & \\
\hline 1 & FDI & -1.28 & -0.97 & -2.91 & $-3.14 *$ & $\mathrm{I}(1)$ \\
\hline 2 & EMR & -0.82 & -1.67 & $-3.71 *$ & - & $\mathrm{I}(1)$ \\
\hline 3 & EXP & -2.21 & -1.61 & $-4.70 * *$ & - & $\mathrm{I}(1)$ \\
\hline 4 & IMP & -2.04 & -1.40 & $-5.08 * *$ & - & $\mathrm{I}(1)$ \\
\hline 5 & EXR & -3.42 & -2.90 & $-5.52 * *$ & - & $\mathrm{I}(1)$ \\
\hline 6 & INF & -2.26 & -3.15 & $-4.22^{*}$ & - & $\mathrm{I}(1)$ \\
\hline
\end{tabular}

Note: From CRITICAL DICKEY-FULLE table, $1 \%$ and $5 \%$ significance level for sample size less than 50 is given as -4.38 and -3.60 respectively. In this table, '**' and '*', represent $1 \%$ and $5 \%$ level of significance respectively.

Table 3.2, on the other hand, shows that all the data are integrated of order I (1) whether the time series are constant or constant with time trend data. This is suggestive of the fact that analysis conducted using the data in $\log$ form might likely yield a truer result than that of linear forms.

TABLE 3.2A UNIT ROOT TEST FOR STATIONARITY WITH CONSTANT ONLY

\begin{tabular}{|c|c|c|c|c|c|c|}
\hline \multicolumn{7}{|c|}{ UNIT ROOT TEST FOR STATIONARITY WITH CONSTANT ONLY } \\
\hline & & \multicolumn{2}{|c|}{ LEVEL } & \multicolumn{2}{|c|}{ 1st Difference } & \multirow[b]{2}{*}{ Conc } \\
\hline & VARIABLES & DF & ADF & DF & ADF & \\
\hline 1 & LN(FDI) & -0.92 & -0.06 & $-4.01 * *$ & - & $\mathrm{I}(1)$ \\
\hline 2 & LN(EMR) & -1.56 & -1.43 & $-3.33 *$ & - & $\mathrm{I}(1)$ \\
\hline 3 & LN(EXP) & -2.44 & -1.80 & $-5.02 * *$ & - & $\mathrm{I}(1)$ \\
\hline 4 & LN(IMP) & -2.05 & -1.85 & $-4.64 * *$ & - & $\mathrm{I}(1)$ \\
\hline 5 & LN(EXR) & -1.72 & -0.98 & $-5.69 * *$ & - & $\mathrm{I}(1)$ \\
\hline 6 & LN(INF) & -1.99 & -1.36 & $-4.43 * *$ & - & $\mathrm{I}(1)$ \\
\hline
\end{tabular}

Note: From CRITICAL DICKEY-FULLE table, $1 \%$ and $5 \%$ significance level for sample size less than 50 is given as -3.75 and -3.00 respectively. In this table, ' $* *$ ' and ' $*$ ', represent $1 \%$ and $5 \%$ level of significance respectively.

TABLE 3.2B UNIT ROOT TEST FOR STATIONARITY WITH CONSTANT AND TIME TREND UNIT ROOT TEST FOR STATIONARITY WITH CONSTANT AND TIME TREND

\begin{tabular}{|c|c|c|c|c|c|c|}
\hline \multicolumn{2}{|c|}{} & \multicolumn{2}{c|}{ LEVEL } & \multicolumn{2}{c|}{ 1st Difference } & ADF \\
\hline & VARIABLES & DF & ADF & DF & Conc \\
\hline 1 & LN(FDI) & -3.33 & -2.45 & $-3.84^{*}$ & - & $\mathrm{I}(1)$ \\
\hline 2 & LN(EMR) & -0.49 & -1.28 & $-3.74^{*}$ & - & $\mathrm{I}(1)$ \\
\hline 3 & LN(EXP) & -2.38 & -1.64 & $-4.90^{* *}$ & - & $\mathrm{I}(1)$ \\
\hline 4 & LN(IMP) & -1.69 & -1.27 & $-4.76^{* *}$ & - & $\mathrm{I}(1)$ \\
\hline 5 & LN(EXR) & $-4.03^{*}$ & - & - & - & $\mathrm{I}(0)$ \\
\hline 6 & LN(INF) & -2.25 & -2.65 & $-4.50^{* *}$ & - & $\mathrm{I}(1)$ \\
\hline
\end{tabular}

Note: From CRITICAL DICKEY-FULLE table, $1 \%$ and 5\% significance level for sample size less than 50 is 
given as -4.38 and -3.60 respectively. In this table, '**' and '*', represent $1 \%$ and $5 \%$ level of significance respectively.

\subsection{GRANGER TEST (VECTOR AUTOREGRESSION MODEL (VAR).}

Do past values of FDI help to explain the present values of EMR? Or do past values of FDI help to predict the present values of EMR? The test is conducted as follows. The first difference of EMR and FDI was taken resulting to the growth equation. The current EMR growth is regressed on all lagged EMR growth terms and other variables in the model, if any. The lagged FDI growth will not be included in this regression. This is called the restricted regression and from this, restricted residual sum of squares, $R S S_{R}$, is obtained. This is the first stage. The second stage involves re-running the first regression but including the lagged terms of FDI growth form. From this regression, the unrestricted sum of squares, $R S S_{U R}$, is obtained. The Akaike information is calculated using the formula below:

$$
A I C=\ln \left(\frac{R S S_{U R}}{T}\right)+\left(\frac{2 j}{T}\right)
$$

where $R S S_{U R}=$ error sum of squares of the unrestricted regression, $\mathrm{T}=$ current time, $\mathrm{j}=$ number of estimated parameters in the unrestricted regression.

The overall goodness of fit is measured by $\mathrm{F}$ values. The $\mathrm{F}$ value here is not, however, the normal $\mathrm{F}$ values embedded ( $\boldsymbol{F}_{\text {output }}$ ) in the regression packages. Instead, the F, generally referred to as $\boldsymbol{F}_{\text {cal }}$ in this project is calculated from:

$$
F_{c a l}=\frac{\left(R S S_{R}-R S S_{U R}\right) / m}{R S S_{U R} /(n-k)}
$$

Where: $R S S_{R}=$ Restricted Sum of Square Residuals

$R S S_{U R}=$ Unrestricted Sum of Square Residuals

$\mathrm{m}=$ Number of the lagged terms of the variable that is being tested for dependability. That is the parameter whose control on the depended variable is being investigated. $n=$ number of observations, $k=$ number of parameters estimated in the unrestricted regression. It is the $F_{c a l}$ that is used to test the goodness of fit of the regression. In order words, if $F_{c a l}$ of a regression is greater than the critical F-values for a regression of the type $F D I_{t} \rightarrow E M R_{t}$, then FDI is said to granger cause EMR and otherwise if not.

\subsection{TRADITIONAL OLS MODEL RESULTS}

\section{Results And Discussion}

The table below presents the results of the ordinary or traditional OLS models. Since this is a reassessment of Salami and Oyewale (2013) submission, it makes sense to compare the results with theirs. Our traditional and standardized OLS results are presented in Tables 4.1 and 4.2 respectively. The constant term, the coefficients of FDI, import and exchange rate of their traditional OLS linear regression are respectively 28.527,

$$
1.48 \times 10^{-8}
$$

0.179 , and 0.059 . They are all positive and compares well with that presented table 4.1. Contrarily, the coefficients of export and inflationary rate are negative in ours whereas they report positive coefficients. While the statistical significance of these coefficients is indicated in table 4.1, the statistical significance of their traditional OLS results is not indicated.

TABLE 4.1: DEPENDENT VARIABLE: EMR

\begin{tabular}{|c|c|c|c|c|}
\hline VARIABLE & COEFFICIENT & S.E & T-VALUE & P-VALUE \\
\hline CONSTANTS & 34.580000 & 3.88 & 2.906 & $2.24 \mathrm{E}-07 * * *$ \\
\hline FDI & 0.000001 & 0.0000005 & 3.855 & $0.02392 *$ \\
\hline IMP & 0.264100 & 0.0685 & -1.255 & $0.00156 * *$ \\
\hline EXP & -0.046530 & 0.0371 & 0.391 & 0.22873 \\
\hline EXR & 0.007694 & 0.0197 & -0.331 & 0.70152 \\
\hline INF & -0.005642 & 0.0171 & 0.74526 \\
\hline
\end{tabular}


Note: '***', '**' and '*' imply significant at $0 \%, 0.1 \%$ and $1 \%$

Multiple R-squared: 0.8945, Adjusted R-squared: 0.8593, F-statistic: 25.43 , DW $=1.778055$

4.2 RESULTS OF THE STANDARDIZED LINEAR REGRESSION MODEL

Table 4.2 presents the results of the standardize regression model. Gujarati (2004) asserts that all the variables in a regression are put on equal basis when the variables are standardized. The implication for this is that all the coefficients can be compared directly with one another. If the coefficient of one standardized regressor is larger than that of another standardized regressor appearing in the model, then the former contributes more relatively to the explanation of the regressand than the latter. The intercept term of a regression involving standardized regressand and regressors is generally zero.

While the economic significance of the variables in tables 4.1 remains the same in table 4.2 , their statistical significance differs dramatically. While the coefficient of FDI in Table 4.1 and in the report of Salami and Oyewale (2013) are infinitesimal, the result of the regression on the standardized variable shows that FDI makes the highest contribution to Nigeria employment status. While the standardized beta coefficients of Salami and Oyewale (2013) suggest that exchange rate makes the greatest positive and significant contribution to employment rate, table 4.2 shows that that is not the case. Again, positive sign of inflationary rate in their investigation implies that inflation stimulates employment in Nigeria. This, of course, will be taken with a pinch of salt by policymakers. Interestingly, the table below equally shows that inflation impacts negatively on the economy of Nigeria. How about the negative role of export as observed in table 4.2? Surely, policymakers would be in dilemma if export retards Nigerian economic progress. There is, thus, a need for validation of these results.

TABLE 4.2: DEPENDENT VARIABLE: EMR

\begin{tabular}{|c|c|c|c|c|}
\hline VARIABLE & COEFFICIENT & S.E & T-VALUE & P-VALUE \\
\hline FDI & 0.737060 & 0.28408 & 2.595 & $0.01955 *$ \\
\hline IMP & 0.392540 & 0.09859 & 3.982 & $0.00107 * *$ \\
\hline EXP & -0.153640 & 0.11855 & -1.296 & 0.21336 \\
\hline EXR & 0.120100 & 0.29765 & 0.403 & 0.69192 \\
\hline INF & -0.036750 & 0.10753 & -0.342 & 0.73695 \\
\hline
\end{tabular}

Note: '***', '**' and '*' imply significant at $0 \%, 0.1 \%$ and $1 \%$

Multiple R-squared: 0.8945, Adjusted R-squared: 0.8615, F-statistic: 27.13, DW = 1.778055

\subsection{RESULT VALIDATION/COINTEGRATION TEST}

Recall that the result of stationarity test in tables 3.1 shows that FDI contains unit root. The results of analysis conducted with such variables should be taken with caution as it might be spurious. Wilhelms and Witter (1998), whose work is partly similar to ours, submit that the robustness of unlogged regression results could be tested by using the semi-logged (linear-log) and the logged forms of the variables. Following this indications, we present the standardized OLS result of the log-log forms of the variables in table 4.3.

A comparison of tables 4.2 and 4.3 reveals not only interesting differences between the linear regressions OLS and the log-log forms but it also indicates some good similarities. The coefficient of export is now positive. Although the coefficient of exchange rate remains positive in the two tables, the log-log form regression form shows a higher contribution of exchange rate to employment rate. Also, table 4.2 shows that import is more statistically significant (significant at $0.1 \%$ ) than FDI, table 4.3 flaws the find. Instead, both are shown to be statistically significant at the same level with FDI making the highest contribution to the dependent variable. It is important to recall that the result of the unit root test differs for the two forms of the variables. While that of the linear form contain unit root (table 3.1A), there is no unit root when the $\log$ forms of the variables are used. These could be the sources of the differences between the results presented in table 4.2 and 4.3 .

It might be needful to consider the presence of autocorrelation in all these results before concluding that the result of table 4.3 is valid. The Durbin-Watson (DW) test statistic is generally used to test for the presence of autocorrelation in a data. BLUE (Best Linear Unbiased Estimator) property of OLS is lost in the presence of autocorrelation. In fact, autocorrelation is about the worst problem associated with regression analysis. The statistical significance attached to regression results containing autocorrelation is invalid since both $\mathrm{F}$ and $\mathrm{t}$ statistics of the regression are unreliable. Whether a regression result contains autocorrelation or not depends on the closeness or departure of the associated DW statistic to or from 2 respectively. The DW statistic associated with tables 4.2 and 4.3 are respectively 1.778055 and $=2.060574$. This further lends credence to the validity of the log-log regression model as a true representation of the relationship between the explanatory and the dependent variables. The negative sign of inflation equally makes more economic sense than the positive sign reported in table 4.2. 
TABLE 4.3: DEPENDENT VARIABLE: LN (EMR)

\begin{tabular}{|c|c|c|c|c|}
\hline VARIABLE & COEFFICIENT & S.E & T-VALUE & P-VALUE \\
\hline LN(FDI) & 0.54492 & 0.20263 & 2.6890 & $0.0161 *$ \\
\hline LN(IMP) & 0.190040 & 0.08671 & 2.192 & $0.0435 *$ \\
\hline LN(EXP) & 0.042440 & 0.10129 & 0.419 & 0.68080 \\
\hline LN(EXR) & 0.320270 & 0.22660 & 1.413 & 0.17670 \\
\hline LN(INF) & -0.107720 & 0.10619 & -1.014 & 0.32550 \\
\hline
\end{tabular}

Note: '***', '**' and '*' imply significant at $0 \%, 0.1 \%$ and $1 \%$

Multiple R-squared: 0.8967, Adjusted R-squared: 0.8644, F-statistic: 27.78, DW = 2.060574

\section{3 .1 MULTIVARIATE GRANGER CAUSALITY TEST (VECTOR AUTOREGRESSIVE MODEL)}

The results presented so far confirm FDI significantly exert positive impact on the employment rate in Nigeria. The result cannot, however, tell us if it is unemployment/employment rate in Nigeria that causes FDI or whether it is FDI that causes employment. There is, thus, a need to test for the direction of causality between the two economic variables. Other variables in the regression are equally tested to see if there are some bilateral flows between the variables. Using the AIC information, it is calculated that the lag length for the data is 2 . It is interesting to observe that there are strong bilateral flows between FDI and EMR at both lags. While FDI granger caused exchange rate at lag 1 , neither causes the other at lag 2 . The same applies to import and FDI. There is a strong bilateral flow between FDI and export at lag 1 while export granger causes FDI at 2 lag. There is a strong bilateral flow between FDI and inflation at lag 1 whereas only inflation granger causes FDI at lag 2. Another OLS regression, where either FDI or INF is dependent variable is required to interpret whether the causality result between FDI and INF is positive or negative. The result of the regression, not presented, shows that inflationary rate has positive impact on FDI. It is worth noticing that the highest causality occurs from employment rate to export. This is economically plausible. Higher employment rate will surely induce greater productivity and hence more exportation of goods. Another result that is worth a special note is the direction of causality between employment rate and inflation. An increase in inflationary rate will adversely affect employment rate at the period of 1 year lag. The rest of the results can be deduced from table 4.4.

TABLE 4. 4: MULTIVARIATE GRANGER CAUSALITY TEST (VAR)

\begin{tabular}{|c|c|c|c|c|c|c|}
\hline \multirow{2}{*}{$\begin{array}{c}\text { REGRESSION } \\
\text { TYPE }\end{array}$} & $\begin{array}{c}\text { NO OF } \\
\text { LAGS }\end{array}$ & \multirow{2}{*}{$F_{c a l}$} & \multicolumn{4}{|c|}{ Critical F values } \\
\cline { 4 - 7 } & & & $1 \%$ & $5 \%$ & $10 \%$ & $d f_{1} / d f_{2}$ \\
\hline$F D I \rightarrow E M R$ & 1 & $32.61^{* * *}$ & 9.07 & 4.67 & 3.14 & $1 / 13$ \\
\hline$E M R \rightarrow F D I$ & 1 & $10.63^{* * *}$ & 9.07 & 4.67 & 3.14 & $1 / 13$ \\
\hline$F D I \rightarrow E X R$ & 1 & $7.03^{* *}$ & 9.07 & 4.67 & 3.14 & $1 / 13$ \\
\hline$E X R \rightarrow F D I$ & 1 & 1.82 & 9.07 & 4.67 & 3.14 & $1 / 13$ \\
\hline$F D I \rightarrow I M P$ & 1 & $4.88^{* * *}$ & 9.07 & 4.67 & 3.14 & $1 / 13$ \\
\hline$I M P \rightarrow F D I$ & 1 & 2.43 & 9.07 & 4.67 & 3.14 & $1 / 13$ \\
\hline$F D I \rightarrow E X P$ & 1 & $11.32^{* * *}$ & 9.07 & 4.67 & 3.14 & $1 / 13$ \\
\hline$E X P \rightarrow F D I$ & 1 & $36.47^{* * *}$ & 9.07 & 4.67 & 3.14 & $1 / 13$ \\
\hline$F D I \rightarrow I N F$ & 1 & $9.71^{* * *}$ & 9.07 & 4.67 & 3.14 & $1 / 13$ \\
\hline$I N F \rightarrow F D I$ & 1 & $13.98^{* * *}$ & 9.07 & 4.67 & 3.14 & $1 / 13$ \\
\hline$E X R \rightarrow E M R$ & 1 & $81.74^{* * *}$ & 9.07 & 4.67 & 3.14 & $1 / 13$ \\
\hline$E M R \rightarrow E X R$ & 1 & $11.38^{* * *}$ & 9.07 & 4.67 & 3.14 & $1 / 13$ \\
\hline
\end{tabular}




\begin{tabular}{|c|c|c|c|c|c|c|}
\hline$E M R \rightarrow I M P$ & 1 & $10.40 * * *$ & 9.07 & 4.67 & 3.14 & $1 / 13$ \\
\hline$I M P \rightarrow E M R$ & 1 & $54.60 * * *$ & 9.07 & 4.67 & 3.14 & $1 / 13$ \\
\hline$E M R \rightarrow E X P$ & 1 & $303.35^{* * * *}$ & 9.07 & 4.67 & 3.14 & $1 / 13$ \\
\hline$E X P \rightarrow E M R$ & 1 & $12.49 * * *$ & 9.07 & 4.67 & 3.14 & $1 / 13$ \\
\hline$E M R \rightarrow I N F$ & 1 & $11.98 * * *$ & 9.07 & 4.67 & 3.14 & $1 / 13$ \\
\hline$I N F \rightarrow E M R$ & 1 & 159.56 *** & 9.07 & 4.67 & 3.14 & $1 / 13$ \\
\hline$F D I \rightarrow E M R$ & 2 & $29.94 * * *$ & 8.65 & 4.46 & 3.11 & $2 / 8$ \\
\hline$E M R \rightarrow F D I$ & 2 & $3.29^{*}$ & 8.65 & 4.46 & 3.11 & $2 / 8$ \\
\hline$F D I \rightarrow E X R$ & 2 & 0.48 & 8.65 & 4.46 & 3.11 & $2 / 8$ \\
\hline$E X R \rightarrow F D I$ & 2 & 1.91 & 8.65 & 4.46 & 3.11 & $2 / 8$ \\
\hline$F D I \rightarrow I M P$ & 2 & 1.98 & 8.65 & 4.46 & 3.11 & $2 / 8$ \\
\hline$I M P \rightarrow F D I$ & 2 & 0.86 & 8.65 & 4.46 & 3.11 & $2 / 8$ \\
\hline$F D I \rightarrow E X P$ & 2 & 2.43 & 8.65 & 4.46 & 3.11 & $2 / 8$ \\
\hline$E X P \rightarrow F D I$ & 2 & $9.89^{* * *}$ & 8.65 & 4.46 & 3.11 & $2 / 8$ \\
\hline$F D I \rightarrow I N F$ & 2 & 0.79 & 8.65 & 4.46 & 3.11 & $2 / 8$ \\
\hline$I N F \rightarrow F D I$ & 2 & $3.12^{*}$ & 8.65 & 4.46 & 3.11 & $2 / 8$ \\
\hline$E X R \rightarrow E M R$ & 2 & $42.88 * * *$ & 8.65 & 4.46 & 3.11 & $2 / 8$ \\
\hline$E M R \rightarrow E X R$ & 2 & $3.55^{*}$ & 8.65 & 4.46 & 3.11 & $2 / 8$ \\
\hline$E M R \rightarrow I M P$ & 2 & $3.39^{*}$ & 8.65 & 4.46 & 3.11 & $2 / 8$ \\
\hline$I M P \rightarrow E M R$ & 2 & $61.51 * * *$ & 8.65 & 4.46 & 3.11 & $2 / 8$ \\
\hline$E X P \rightarrow E M R$ & 2 & $114.66^{* * * *}$ & 8.65 & 4.46 & 3.11 & $2 / 8$ \\
\hline$E M R \rightarrow E X P$ & 2 & $3.85^{*}$ & 8.65 & 4.46 & 3.11 & $2 / 8$ \\
\hline$E M R \rightarrow I N F$ & 2 & $3.57^{*}$ & 8.65 & 4.46 & 3.11 & $2 / 8$ \\
\hline$I N F \rightarrow E M R$ & 2 & $48.17 * * *$ & 8.65 & 4.46 & 3.11 & $2 / 8$ \\
\hline
\end{tabular}

Note: '***', '**', and '*', represent significant at 1\%, 5\%, and $10 \%$ level of significance. The fraction, $d f_{1} / d f_{2}$, represents degrees of freedom (numerator and denominator respectively). It is used to reference upper (critical) points of the F Distribution table.

\subsubsection{LAGGED OLS}

Another way of validating the result of table 4.3 is by the use of lagged values of FDI. As indicated earlier, the lagged values of FDI are needed to explain the role of foreign investment on the economy of a nation. Table 4.5 presents the result of 1 year lag period of these variables as predictors of employment. While 
the sign of all the variables remain the same as previously reported, the contribution of FDI is not only the largest, but also the only variable that impacts significantly on the employment rate in Nigeria. But a closer look at the statistics of the table suggests that the result is not quite reliable. This is due to the presence of autocorrelation as indicated by the DW statistic. The DW statistic that is far below two implies a strong negative autocorrelation and would strongly bias the OLS result. The serious bias introduced by autocorrelation to this result will be more evident in the light of table 4.3 which confirm that import has a significant impact on employment rate in Nigeria. If the result of 4.5 is misleading, what will be the right lagged OLS model?

FDI, due to the official bottle neck or red tape in Nigeria from registration to actual operations requires incubation or gestation period to start influencing the economy whereas other variables in the model may not need any time lag to impact on the economy of the nation. Armed with these indications, another lag dependent OLS is conducted and the results presented in Table 4.6.

TABLE 4.5: DEPENDENT VARIABLE: $E M R_{t}$

\begin{tabular}{|c|c|c|c|c|}
\hline VARIABLE & COEFFICIENT & S.E & T-VALUE & P-VALUE \\
\hline$F D I_{t-1}$ & 0.667270 & 0.23885 & 2.794 & $0.0144 *$ \\
\hline$I M P_{t-1}$ & 0.075680 & 0.11924 & 0.635 & 0.53590 \\
\hline$E X P_{t-1}$ & 0.091700 & 0.10180 & 0.901 & 0.38300 \\
\hline$E X R_{t-1}$ & 0.165460 & 0.29162 & 0.567 & 0.57940 \\
\hline$I N F_{t-1}$ & -0.188010 & 0.14839 & -1.267 & 0.22580 \\
\hline
\end{tabular}

Note: '***', '**' and '*' imply significant at $0 \%, 0.1 \%$ and $1 \%$

Multiple R-squared: 0.8541, Adjusted R-squared: 0.802, F-statistic: 16.39, DW = 1.144434

A number of inferences could be drawn from table 4.6 with respect to the validity of the result. First, the DW statistics is just about 2, confirming that the result is valid as it is free from autocorrelation. This contrast very well with that of table 4.5 whose DW statistics is far below 2. In addition to the result telling the story of the time lag between FDI project take off and the time it starts benefiting the economy, the absence of autocorrelation in the result also shows that lagged values of FDI is a good instrumental for FDI variable. Another important observation from table 4.6 is that its result is a reflective of that presented in table 4.3. The coefficient of FDI remains the largest and the most statistically significant variable that determines the rate of employment in Nigeria. The result gives great insight as it points to FDI theory as an imperative compass in empirical analyses.

Second, table 4.3 tells us that importation of goods encourages employment in Nigeria whereas table 4.6 shows a negative impact. Which of the result is true? It was already pointed out that the presence of autocorrelation is the major difference between the two results. While the results of table 4.3 may be a little biased due to autocorrelation, the absence of autocorrelation in table 4.6 makes the result more appealing. What is the economic light in this? Is importation of goods really expected, aprori, to impact negatively on the economy of any nation? The answer is yes, or no, depending on the type of economy and the types of good imported into that economy. Importation of finished goods, for instance, will surely negate the rate of employment. On other hand, raw materials imported into the country will surely boost employment. This result will, doubtlessly, have far reaching policy implications in Nigeria as it points to the cause of the incurable employment problem that paralyzes the country for decades now. Instead of importing raw materials for industries, the result confirms that readymade goods are mostly imported into the country.

Third, the coefficient of exchange rate does not only remain larger than that of export in table 4.6 but is also significant, suggesting that the rank of employment determinants in Nigeria increases from export, exchange rate to FDI.

Forth, there is also an improvement in the negative role of inflation in this table. While table 4.3 shows that $1 \%$ increase in inflation rate will lead to $0.11 \%$ fall in employment rate, table 4.6 confirms that the negative impact of inflation on employment rate is not that bad. A percentage increase in inflation rate will only induce $0.08 \%$ decrease in employment rate. 
TABLE 4.6: DEPENDENT VARIABLE: $E M R_{t}$

\begin{tabular}{|c|c|c|c|c|}
\hline VARIABLE & COEFFICIENT & S.E & T-VALUE & P-VALUE \\
\hline$F D I_{t-1}$ & 0.55430 & 0.11050 & 5.016 & 0.000189 *** \\
\hline$I M P_{t}$ & -0.03382 & 0.07810 & -0.433 & 0.671571 \\
\hline$E X P_{t}$ & 0.16195 & 0.07191 & 2.252 & $0.021332 * 888^{*}$ \\
\hline$E X R_{t}$ & 0.30769 & 0.11874 & 2.591 & 0.322528 \\
\hline
\end{tabular}

Note: '***', '**' and '*' imply significant at $0 \%, 0.1 \%$ and $1 \%$

Multiple R-squared: 0.9325, Adjusted R-squared: 0.9084 ,

F-statistic: $138.71, \mathrm{DW}=2.088851$

\section{Conclusions And Policy Perspectives}

The debate on the role of FDI on the economy of the host countries started right from the inception of multinational corporations (MNCs) - over six decades. As a rule, solutions or answers will surely be found for any problem - be it the most incurable/chronic disease or any sort of academic exercise - that last so long. FDIeconomic growth studies appear to defile this rule. Instead of the debate waning, it is becoming fiercer. The present work, nonetheless, shows that firmed and unbiased conclusions can be reached on the implications of FDI on Nigeria's economy. However, any such assertive and unbiased conclusions cannot be possible with a single regression model specification which is observed in a vast volume of FDI-growth empirical literatures. Salami and Oyewale (2013), for example, previously investigated the role of FDI on employment rate in Nigeria using only a single regression model on the same data. Quite contrary to our results, they argue that FDI plays no significant role on employment rate in Nigeria. This is distressing as such biased findings will classify Nigeria among the few unlucky countries whose economy refuses to go, even in the phase of FDI, which is globally accepted as an engine of growth.

The bane of investigating FDI-growth relation lies in, among other things, the presence of unit root, the bias introduced by autocorrelation to OLS estimates, the error arising from traditional OLS models and the negligent of the imperative FDI-growth lag dependent. Instead of using a single model to investigate the data, the present work employs 8 different regression models in a bid to arrive at a true conclusion. A comparison of the two results do not only show some bewildering differences but it will also vindicate the claim that detailed analyses are required to predict the true part of FDI in the economy of Nigeria.

The policy implications of these findings are obvious. Above every other thing, the government should lay much emphasis on FDI attraction into the country in order to minimize the high rate of unemployment that pins down the economy of Nigeria. Conscious efforts should be made to discourage the importation of readymade goods into the country. Importation of raw materials is what Nigeria needs as it will, contrary to the effects of finished goods importation, encourage both local and foreign firms' productivity, favour employment as well as exportation of goods to other nations of the world.

\section{References}

[1]. Adofu, I., (2010). Accelerating Economic Growth in Nigeria, The Role of Foreign Direct Investment. Current Research Journal of $\begin{array}{ll}\text { Economic Theory 2(1): } 11-15 & 15\end{array}$

[2]. Abu, M., and Achegbulu, J. O., 2011, An investigation of the impact of foreign direct investment on economic growth of Nigeria, International Business and Management, Vol. 3, No. 1, pp 232-238.

[3]. Aluko, S.A. (1961). "Financing economic development in Nigeria". The Nigerian Journal of Economic and Social Studies, 3(1): $39-67$.

[4]. Amadi, S.N., (2002), The impact of macroeconomic environment on Foreign Direct Investment in Nigeria, Int. J. Dev., 4(2)

[5]. Andren, T., (2007). Econometrics, Thomas and Andren Ventures Publishing ApS.

[6]. Anyanwu, J.C. (1998). "An econometric investigation of determinants of foreign direct investment in Nigeria". In Investment in the Growth Process: Proceedings of the Nigerian

[7]. Economic Conference 1998, pp. 219-40. Ibadan, Nigeria

[8]. Aremu, J.A.(1997), Foreign Private investment: Issues, Determinants and Performance, A Paper Foreign investment policy and practice, organized by the Nigeria Institute of Advance Legal

presented at a workshop on Studies, Lagos, March. 
[9]. Ariyo, A. 1998, Investment and Nigeria's economic growth. In investment in the Growth Process $\quad$ Proceedings of Nigeria Economy Society Annual Conference 1998, pp.389-415. Ibadan, Nigeria.

[10]. Asiedu, E. (2002). On the Determinants of Foreign Investment to Developing Countries: is Africa Different? World Development, 30 , No $1,107-9$

[11]. Ayanwale, A.B., (2007). FDI and Economic Growth: Evidence from Nigeria. .AERC Research paper 165, African Economic Research Consortium, Nairobi.

[12]. Badeji , B. O., and Abayomi, O. M., The Impact of Foreign Direct Investment on Economic Growth in Nigeria International Research Journal of Finance and Economics 73 (2011) http://www.eurojournals.com/finance.htm

[13]. Brown, C.V. (1962). "External economies and economic development". The Nigerian Journal of Economic and Social Studies, 4(1): 16-22.

[14]. Chete, L.N. (1998) "Determinants of foreign Direct Investment in Nigeria", The Nigerian

[15]. Journal of Economics and Social Studies Vol. No1

[16]. Chingarande, A. Et al. (2012). The impact of interest rates on Foreign direct investment. A case study on the Zimbabwean economy (Febrary 2009-June 2011). International Journal of Management Sciences and Business Research vol.1, No.5

[17]. Dolan, et al., (1991). Foreign Investment as a Tool for Accelerating Economic Growth in Less Developed Countries the Nigerian Experience. In: Unpublished B.Sc Project Department of Economics, Kogi State University. K.E . Elebiyo, (Ed.), (2004). Anyigba, .Nigeria.

[18]. Gujarati, (2004), Basic Econometrics, fourth edition. The McGraw-Hill Companies.

[19]. Hymer, S.H., (1960). The International Operations of National Firms. A study of Direct Foreign Investments. PhD Dissertation. Published Posthumously The MIT Press, (1976). Cambridge, Mass.

[20]. Katerina, L., Paranastasiou, J., Athanasios, V., (2004). Foreign Direct Investment and $\quad$ Economics.South Eastern Journal of Economics, 1, 97-110.

[21]. Keller, W. (1996). Absorptive capacity: on the creation and acquisition of Technology in Development. Journal of Development Economics, 49, 199-227

[22]. Lipsey, R.G., (1986). An Introduction to Positive Economics. $6^{\text {th }}$ Edn. Weidenfeld and Nicolson, London

[23]. Lensink, R and Morrisey, O. (2001). Foreign direct investment: Flows, volatility and growth in developing countries. Globalization and Poverty DESG 2001. 32p, Nottingham.

[24]. Makola, M., 2003, The Attraction of the Foreign Direct Investment (FDI) by the African Countries, Biennial ESSA Conference, Sommerset West: Cape Town, 17-19 September.

[25]. Obinna, O.E., (1983), Diversification of Nigeria's external finances through foreign direct investment. Nigerian Econometric Society Annual Conference Proceedings, JOS, 13-16 $6^{\text {th }}$ May.

[26]. Ojo, M.O. (1998), Developing Nigeria Industrial Capacity: via Capital Market, Abuja, CBN Bulletin Vol. 22, No. 3 July/Sept.

[27]. Okon, J. U., Augustine, O. U., and Chuku, A.C. (2012), Foreign Direct Investment and Economic Growth in Nigeria: An Analysis of the Endogenous Effects. Current Research Journal of Economic Theory 4(3): 53-66

[28]. Onu, A.J.C. (2012). Impact of Foreign direct investment of economic growth in Nigeria. Interdisciplinary Journal of contemporary Research in Business, vol. 4, No. 5

[29]. Oseghale,B.D. and Amenkhienan, F.E. (1987) "Foreign Debt, Oil Exports and Direct Foreign

[30]. Investment and Economic Performance" Nigerian Journal of Economic Studies, Vol.29, No3.

[31]. Otepola A (2002). Foreign Direct Investment as a factor of Economic Growth in Nigeria.

[32]. Oyaide, W.G., (1977). The Role of Direct Foreign Investment: A case study of Nigeria, (1963-

[33]. 1973). United Press of America, Washington D.C.

[34]. Oyinlola, O. (1995). "External capital and economic development in Nigeria (1970-1991)".

[35]. Oyatoye, E.O., Arogundade, K.K., Adebisi, S.O., and Oluwakayode, E.E., (2011), Vol. 2, No. 1.

[36]. Quazi, R. M. (2007). Investment Climate and Foreign Direct Investment study of selected countries in Latin America. Global Journal of Business Research, 1(2), 1-13

[37]. The Nigerian Journal of Economic and Social Studies, 37(2\&3): 205-22.

[38]. Robu, R.G.P. (2010), The impact of foreign direct investments on labour productivity: A review of the evidence and implications, The Romanian Economic Journal, no. 36

[39]. Root, F.R., (1984) . International Trade and Investment. $5^{\text {th }}$ Edn. South Western Publication Company, Cincinnati, Ohio

[40]. Smith, S. (1997). Restrictive policy towards Multinationals: Argentina and Korea. Case studies is Economic Development, 2,178189.

[41]. Tadaro, M.P., (1999). Economic Develop men t. 7th Ed n., Addison Webley Longman Inc. Reading. Massachusetts

[42]. Ugwuegbe, S.U., Okoro, A. O., Onoh, J.O., The impact of Foreign Direct Investment on the Nigeria Economy. European Journal of Business and Management, Vol. 5. No. 2, 2013.

[43]. Umah, K.E. (2002), The Direct of Foreign Private on Economic Development of Nigeria, Nigeria Journal of Economics and Financial research Vol. No.3.

[44]. Umah, K.E. (2007), The Impact of Foreign Private Investment on Economic Development of Nigeria, Nigeria Journal of Economics and Financial research. Vol. 1, No.3

[45]. Wilhelms and Witter (1998) foreign direction investment and its determinants in emerging economics. African Economic Policy Paper Discussion Paper Number 9

[46]. Worl Bank, (1996), World Debt Tables: External Finance for Developing Countries, Vol. 1 (Analysis and Summary Tables). Washington, D.C.: The World Bank.

[47]. Xu, B. (2000). Multinational Enterprises Technology Diffusion and Host country productivity growth. Journal of Economics, 62, $477-493$ 